\title{
The early detection of congenital malformations of the heart
}

\author{
Hamish Watson \\ From the Department of Cardiology, University of Dundee
}

It is a great pleasure to contribute to this special number of the British Heart fournal that celebrates on his 8oth birthday Maurice Campbell's contribution to so many aspects of cardiology. Though his association with the establishment of the British Cardiac Society, the British Heart fournal, and the British Heart Foundation has given him special pleasure, it is probably by his classical papers on congenital malformations of the heart that he will long be remembered. That his interest in the subject did not begin until he was in his early fifties should be a constant encouragement to those searching for ideas, and who are so often told nowadays that relearch effort is bound to fall away in middle life. Campbell's studies on the natural history of various lesions have necessarily been restricted to childhood, adolescence, and adult life. Today, with the emphasis very much on the newborn period, it seems appropriate to say something about their early detection, a field he would certainly have relished had the opportunity been afforded.

- As knowledge about congenital malformations of the heart has accumulated, the necessity for their early detection has become increasingly obvious, and it is now clear that early detection is important not only for the individual so far as prognosis is concerned, but also for the community so that medical care may be planned at local, national, or even international levels. Early detection, however, cannot be considered separately from incidence. Ideally, they should be virtually synonymous because only when all malformations are detected soon after birth can their true incidence, and consequently their natural history, become properly established.

Although the true incidence has almost certainly remained constant, the published figures have shown a fairly steady increase during the past 25 years. Until recently, widely diverse figures, many of which grossly underestimate the number of those born with zardiac malformations, have left the total inci- dence and the incidence of the various malformations somewhat uncertain. Many surveys had failed to give the correct answers either because the methods used - birth and death certificates, hospital referrals, etc. - did not cast the net widely enough or because many with malformations went undetected, having been overlooked in the neonatal period and inadequately followed during childhood and adolescence.

Some malformations are not easily detected soon after birth, some become modified or disappear during infancy and childhood, and many that cause death in the first few weeks or months of life are not recognized as such. Landtman (1971), for example, reviewing the experience in Helsinki of $\mathbf{7 7 7}$ deaths between 1947 and 1970, has reported that in so many as 6I per cent of those who died during the first week of life the congenital cardiac malformation came as a necropsy surprise. To find the true incidence requires detailed assessment at birth and continuous follow-up over many years by experienced cardiologists skilled in this type of practice.

Several intensive studies published during the past few years from different parts of the world have shown fairly similar results and suggest an incidence of around 8 per 1000 live births (Table $\mathrm{I}$ ).

TABLE I Incidence of congenital cardiac malformations per rooo live births: intensive studies

\begin{tabular}{lllrl}
\hline Reference & $\begin{array}{l}\text { Period of } \\
\text { study }\end{array}$ & Place & $\begin{array}{l}\text { Live } \\
\text { births }\end{array}$ & $\begin{array}{l}\text { Incidence } \\
\text { per IO00 }\end{array}$ \\
\hline Richards et al. (I955) & I946-53 & New York & 5,628 & $7 \cdot 6$ \\
Neel (1958) & I948-54 & Japan & 64,569 & $7 \cdot 0$ \\
Carlgren (I959) & I941-50 & Gothenburg & 58,105 & $6 \cdot 3$ \\
Landtman (I965) & I945-50 & Helsinki & I,745,419 $8 \cdot 0$ \\
Kerrebijn (1966) & I958 & Leiden & 1,817 & $8 \cdot 25$ \\
Carlgren (I969) & I95I-60 & Gothenburg & 58,314 & $7 \cdot 7$ \\
Mitchell et al. (I97I) & I960-70 & I2 centres, USA & 54,765 & $7 \cdot 7$ \\
& & & & \\
\hline
\end{tabular}


These figures, though somewhat higher than those currently used for forward planning, almost certainly underestimate the total incidence because allowance must be made for such lesions as atrial septal defects which are seldom detected in the newborn. Richards et al. (1955), for example, had only I atrial septal defect in a total of 43 cases whereas atrial septal defects account for 10-20 per cent of all cases in most series of older children. Many babies with ventricular septal defects, too, escape detection early in life because until the pulmonary vascular resistance falls they have few physical signs and, if asymptomatic after discharge from hospital, the defect may have closed spontaneously or have become so small as to be classified as an innocent murmur by the time they are seen at follow-up clinics. The same may be said for many babies with a ductus arteriosus, though the differentiation between delayed closure of the ductus and spontaneous closure of a persisting ductus is a nice point. Recent proof that atrial septal defects may close spontaneously must also be taken into account. It now seems likely that about I per cent of all babies born alive have some cardiac malformation.

The total incidence of congenital cardiac malformations must, of course, take account of those who are not born alive. Accurate figures for stillbirths are difficult to obtain because diagnosis depends upon necropsy proof, and incidence probably varies with the size of the conceptus. All are now agreed that the incidence is higher in stillbirths than in live births, and Mitchell, Korones, and Berendes (1971), who had an incidence of 7.7/1000 in 54,765 live births, had about ro times this number, $73.5 / 1000$, in 1344 stillbirths, with a necropsy rate of 93 per cent; a stillbirth being defined as the non-liveborn product of a pregnancy whose gestation was of 20 weeks or more.

Published figures for the incidence of the various malformations, like those for total incidence, have varied considerably depending upon the bias given them from their source of origin, necropsy and hospital series naturally showing a higher percentage of severe lesions than those derived from intensive population screening. Good accounts of these and their interpretation are given by Campbell (I968a, b, c, d), by Hoffman (I968), by Rowe and Mehrizi (1968), and by Landtman (I97I). Similarly, mortality rates are probably too high in most series published from hospitals because they contain referrals from sources other than their own nurseries. Eighty-six per cent of Landtman's 777 deaths occurred before the first birthday and 56 per cent of them in the first month. Rowe found that 34 per cent of 100 consecutive cases died in the first month of life between 1960 and I963 in New Zealand, the same figure as that given by MacMahon, McKeown, and Record for Birmingham, England, in 1953. Recent reports by Carlgren (1969) and Mitchell et al. (I97I), who tried to detect all malformations and therefore include many that would not have reached Landtman or Rowe, show far fewer early deaths and are also remarkably similar in this regard, as they are for incidence, and probably give a much truer picture; 24.6 per cent of the Swedish and 29 per cent of the American babies died in the first year of life, 6I per cent of the latter in the neonatal period (Table 2).

This very high mortality from severe congenital cardiac malformation in the first few weeks of life, vouched for by all who are concerned with heart disease in children, emphasizes the importance of early detection. If lives are to be saved, a diagnosis must be made and treatment initiated as soon as possible after birth. All babies should, therefore, be carefully examined before leaving hospital, or soon after birth if born outside hospital, by a paediatrician who is skilled in the detection of congenital malformations and referred to a cardiologist if a cardiac abnormality is suspected. Intensive medical treatment, and in some cases surgery, can prevent considerable loss of life at this stage by allowing time for the situation to be carefully assessed and by giving babies with abnormal cardiovascular systems time to come to terms with extrauterine life. In emphasizing that the experience of special units tends to over-dramatize the neonatal death rate from cardiac malformations so far as their overall incidence in the general population is concerned, it should also be remembered that a large percentage of those

TABLE 2 Death rates in infants with congenital cardiac malformations

\begin{tabular}{|c|c|c|c|c|}
\hline & I week & $I$ month & 6 months & I year \\
\hline \multicolumn{5}{|l|}{ Landtman (I97I) } \\
\hline $\begin{array}{l}777 \text { who died in hospital } \\
\text { Rowe and Mehrizi (I968) }\end{array}$ & $32 \%$ & $53 \%$ & $78 \%$ & $86 \%$ \\
\hline $\begin{array}{l}\text { Ioo referred to special unit } \\
\text { Carlgren (I969) }\end{array}$ & $18 \%$ & $34 \%$ & $49 \%$ & $52 \%$ \\
\hline $\begin{array}{l}450 \text { born alive }(7 \cdot 7 / 1000) \\
\text { Mitchell et al. (1971) }\end{array}$ & $9 \%$ & $14 \%$ & $21 \%$ & $24 \%$ \\
\hline 420 born alive $(7 \cdot 7 / 1000)$ & & $19 \%$ & & $29 \%$ \\
\hline
\end{tabular}

Landtman's series includes 82 postoperative deaths; 39 under I year with a more tality of 27 per cent; the mortality under 6 weeks of 57 per cent compares with a overall mortality of 5.2 per cent for 1696 heart operations. 
vho do not survive have associated congenital nalformations. Rowe and Mehrizi (1968) tated that the majority of their infants dying $n$ the neonatal period exhibited defects in ther systems, Mitchell et al. (197I) found 30 per cent of all their cases and 46 per cent of he 185 who died had extracardiac malformaions, and Landtman (197I) reported that 45 jer cent of his 777 deaths had extracardiac ongenital malformations, half of them muliple. This problem of babies with multiple nalformations, especially in those with menal subnormality, causes increasing concern Jecause it is now possible to prolong their ives - often, perhaps, without sufficient hought for its likely quality.

Profound circulatory adjustments are necesary after birth as the lungs take over from the lacenta, and throughout this period of tranition the signs produced by many serious :ongenital cardiac malformations are coniderably modified. At birth the pressures in oth ventricles and great arterial trunks are ipproximately equal. During the first few lays of life, while the fetal circulation is ransformed into one depending upon a pulnonary and systemic circuit, many of the ntra- and extracardiac shunting mechanisms ersist and function intermittently as the baby ties or otherwise exerts itself. Until such ime as the pulmonary vascular resistance has allen well below that in the systemic circuit ind the ductus and foramen ovale have closed, ibnormal communications between the two irculations or obstruction to flow through ither of them may be difficult to detect.

Many normal babies show a little internittent cyanosis in the early days of life, and bnormal cyanosis is not always obvious in he neonatal period, producing the slatey,rey colour so often seen in transposition of he great arteries rather than the violet-blue hat so many associate with congenital heart lisease in older age groups. It is well to renember too that abnormal cyanosis is seen in pany conditions unrelated to the heart. Craig 1962), for example, found that only is per ent of newborn infants referred to a special laby care unit because of cyanosis had conenital cardiac malformations (Table 3).

Although many cases of heart disease do tave cyanosis, it should be emphasized that ess than one-third of those born alive with evere congenital cardiac malformations preent as blue babies. The majority, whose signs nay be modified as indicated above, are less asily detected, and doctors responsible for he routine examination of the newborn must ie aware of these modifications if the current igh mortality is to be significantly reduced.
TABLE 3 Causes of cyanosis in 93 newborn infants referred to a special baby care unit (Craig, 1962)

Intracranial lesions

Congenital cardiac malformations

Primary pulmonary dysfunction

Uncomplicated traumatic cyanosis

Mucus obstruction

Hypothermia

Septicaemia or meningitis

Choanal atresia or stenosis

Temporary incoordination of breathing or swallowing

Diaphragmetic hernia

Oesophageal atresia

Unexplained

22
14
12
9
7
6
5
4
4
2
2
6

Serious malformations are likely to be missed if mothers and babies are discharged from hospital a few days after delivery, and under these circumstances an early visit to an Infant Clinic is essential. Large ventricular septal defects, for example, and the large ductus may be thought trivial at this stage, in the absence of a significant shunt. Coarctation of the aorta, either alone or in combination with a ventricular septal defect and a persistent ductus arteriosus, often goes unrecognized. Transposition, tricuspid and pulmonary atresia, and Ebstein's anomaly of the tricuspid valve are liable to be overlooked because they produce few auscultatory signs and, as already mentioned, the first three often present with a slatey-grey colour rather than gross classical cyanosis. Fallot's tetralogy is seldom detected immediately after birth because the cyanosis usually takes some time to become obvious, and, if obstruction to pulmonary blood flow is severe, the systolic murmur often sounds insignificant. Total anomalous pulmonary venous drainage may produce neither murmurs nor cyanosis before causing severe heart failure, and less common disorders such as anomalous coronary arteries, fibroelastosis, and other socalied intrinsic myocardial disorders usually take a little time to become manifest.

Babies with severe congenital cardiac malformations not diagnosed in hospital usually present with feeding difficulties, failure to thrive, or heart failure that is often precipitated by intercurrent infection of the lungs or gastrointestinal tract and often unrecognized until it has become serious. Family doctors should be instructed about the significance of these signs because such babies run a rapid downhill course and have a high mortality.

Those whose malformations are not detected until after infancy are the natural survivors for whom diagnosis and treatment are less urgent. Many will lead normal or near 
normal lives and some will require surgical treatment sooner or later either to reduce disability or to prevent eventual deterioration. 'Their early detection is also important, however, so that the natural history of each type of malformation may be accurately determined.

At present our knowledge about many of them is sketchy, making it difficult to plan treatment or, for that matter, to withhold it. The large number of surgical deaths during or after closure of ventricular septal defects that we now suppose to have been innocent lesions would have had little effect on life expectancy, or might even have closed spontaneously had they been left alone, is a good case in point. One wonders if it is really necessary to ligate the small persistent ductus arteriosus or to close so many of the secundum-type atrial septal defects discovered on routine medical examination.

Intense interest in the newborn period in so many centres will soon fill in the gaps in our knowledge about the natural history of the various malformations in the early weeks and months of life. In the older age groups, most studies suffer because they no longer have a so readily identifiable and captive group of patients. The frequency and natural history of the various malformations has for long been one of Campbell's great interests (Campbell, 1953) and as he reaches 80 he is still following and analysing his own case material (Campbell, I968a, b, c, d, I969a, b, I970a, b, I97I). The Association of European Paediatric Cardiologists, the Scientific Council on Paediatric Cardiology of the International Society of Cardiology, and the American Heart Association are currently studying the natural history of several malformations and will provide valuable information (DuShane and Weidman, 1965; Michaelsson and Swiderski, 1967; Watson, 1970). The patients in these studies, however, have all been selected, either by themselves or by their doctors. Larger and long-term follow-up of the patients identified in such intensive population studies as those of Carlgren (1969) and Mitchell et al. (1971), by including malformations of all degrees of severity, would give a much better overall picture of the various effects, or lack of them, produced by each lesion.

\section{References}

Campbell, M. (1953). The frequency of different types of congenital heart disease. British Heart fournal, $15,462$.

Campbell, M. (1968a). The incidence and later distribution of malformations of the heart. In Paediatric
Cardiology, p. 71. Ed. by Hamish Watson. LloydLuke, London.

Campbell, M. (1968b). Natural history of persistent ductus arteriosus. British Heart fournal, 30, 4 .

Campbell, M. (1968c). The natural history of congenital aortic stenosis. British Heart fournal, 30, 514 .

Campbell, M. (1968d). Calcific aortic stenosis and congenital bicuspid aortic valves. British Heart Fournal, 30, 606.

Campbell, M. (I969a). Natural history of congenital pulmonary stenosis. In Proceedings of the British Cardiac Society. British Heart fournal, 31, 394.

Campbell, M. (1969b). The outlook with bundlebranch block. British Heart fournal, 31, 575.

Campbell, M. (I970a). Natural history of coarctation of the aorta. British Heart fournal, 32, 633

Campbell, M. (1970b). Natural history of atrial septal defect. British Heart fournal, 32, 820.

Campbell, M. (1971). Natural history of ventricular septal defect. British Heart fournal, 33, 246.

Carlgren, L.-E. (1959). The incidence of congenital heart disease in children born in Gothenburg 194I-1950. British Heart fournal, 21, 40.

Carlgren, L.-E. (1969). The incidence of congenital heart disease in Gothenburg. Bulletin of the Association of European Paediatric Cardiologists, $5,2$.

Craig, W. S. (1962). Admissions and re-admissions from district to the special baby-care unit of a maternity hospital. British Medical fournal, 2, I 139.

DuShane, J. W., and Weidman, W. H. (1965). Five congenital cardiac defects: a study of the profile and natural history. Circulation, 32, Suppl. III-I.

Hoffman, J. I. E. (1968). Natural history of congenital heart disease. Circulation, 37, 97.

Kerrebijn, K. F. (1966). Incidence in infants and mortality from congenital malformations of the circulatory system. Acta Paediatrica Scandinavica, 55, 316.

Landtman, B. (1965). Epidemiological aspects of congenital heart disease. Acta Paediatrica Scandinavica, 54, 467.

Landtman, B. (1971). Clinical and morphological studies in congenital heart disease. A review of 777 cases. Acta Paediatrica Scandinavica, Suppl. 213.

MacMahon, B., McKeown, T., and Record, R. G. (1953). The incidence and life expectation of children with congenital heart disease. British Heart Fournal, 15, $12 \mathrm{I}$.

Michaelsson, M., and Swiderski, J. (1967). High degree atrio-ventricular block in children - a preliminary report of a joint study with special reference to the natural history. Bulletin of the Association of European Paediatric Cardiologists, 3, 44.

Mitchell, S. C., Korones, S. B., and Berendes, H. W. (1971). Congenital heart disease in 56,109 births. Incidence and natural history. Circulation, 43, 323.

Neel, J. V. (1958). Study of major congenital defects in Japanese infants. American fournal of Human Genetics, 10, 398.

Richards, M. R., Merritt, K. K., Samuels, M. H., and Langmann, A. G. (1955). Congenital malformations of the cardiovascular system in a series of 6053 infants. Pediatrics, 15, 12.

Rowe, R. D., and Mehrizi, A. (1968). The Neonate with Congenital Heart Disease. W. B. Saunders, Philadelphia.

Watson, H. (1970). The natural history of Ebstein's anomaly of the tricuspid valve in childhood and adolescence. Abstracts of VI World Congress of Cardiology. Cardiovascular Research, p. 27. 
the ball and strike it to the point of an audible sound.

\section{References}

Hultgren, H. N., and Hubis, H. (1965). A phonocardiographic study of patients with the Starr-Edwards mitral valve prosthesis. American Heart fournal, 69, 306.

Leachman, R. D., and Cokkinos, D. V. P. (1969). Absence of opening click in dehiscence of mitralvalve prosthesis. New England fournal of Medicine, 28I, $46 \mathrm{I}$.

Starr, A., Herr, R. H., and Wood, J. A. (1967). Mitral replacement; review of six years experience. fournal of Thoracic and Cardiovascular Surgery, 54, 333. Starr, A., Pierie, W. R., Raible, D. A., Edwards, M. L., Siposs, G. G., and Hancock, W. D. (1966). Cardiac valve replacement. Circulation, 33 and 34, Suppl. I, I-II5.

Yacoub, M. H., and Keeling, D. H. (I968). Chronic haemolysis following insertion of ball-valve prostheses. British Heart fournal, 30, 676.

Zitnik, R. S., and Burchell, H. B. (1963). A phonocardiographic study of patients with total prosthetic mitral valve replacement. Diseases of the Chest, 44, II.

Requests for reprints to Dr. Christ Aravanis, 47 Vasilissis Sophias Ave., Athens 140, Greece.

\section{Erratum}

The article, The early detection of congenital malformations, by $\mathrm{H}$. Watson, which appeared in the January issue of this journal (vol. 34, pages 3740) "contains a fairly major error. Page 38 , lines 39-40, left-hand column, should read-'had almost 4 times this number, $27.5 / 1000$, in 1334 stillbirths'. 